\title{
Bacterial patterns found in surgery patients with chronic sinusitis
}

\author{
W. HADLEY HOYT III, DO
}

Aseptic samples of sinus mucosa or aspirates from maxillary sinuses were taken from 197 patients who underwent sinus surgery and were cultured for aerobic bacteria. Anaerobic cultures were also obtained from 143 of these patients. A total of 236 bacterial isolates from 174 patients were analyzed. No anaerobic organisms were isolated. The most commonly isolated organisms were Staphylococcus species (coagulase-negative), Staphylococcus aureus, gram-negative bacilli, and Streptococcus species. Penicillin G, erythromycin, tetracycline hydrochloride and, to a lesser degree, first-generation cephalosporins were found to be inferior to ciprofloxin, trimethoprim/sulfamethoxazole, and cefuroxime axetil when the susceptibilities of all the bacterial isolates to oral antibiotics used commonly in the empiric therapy of chronic sinusitis were compared.

(Key words: Chronic and recurrent bacterial sinusitis, surgery for chronic sinusitis, resistance to antibiotics, anaerobic bacterial sinusitis, aerobic bacterial sinusitis)

Prolonged or repeated episodes of acute sinusitis may lead to irreversible changes in the sinus mucosa resulting in chronic sinusitis. ${ }^{1}$ A review of the medical literature indicates

This investigation was first presented as a free paper at the First International Symposium of Contemporary Sinus Surgery, Pittsburgh, Pa, November 4, 1990.

Reprint requests to W. Hadley Hoyt III, DO, Wilden Clinic, Suite A, 717 Lyon St, Des Moines, IA 50309. that anaerobic bacteria are an important cause of chronic sinusitis..$^{2-7}$ However, studies by the author $^{8}$ and others ${ }^{9,10}$ do not confirm the role of anaerobic organisms; instead, they indicate a much greater incidence of aerobic pathogens than previously reported.

Medical treatment of chronic and recurrent acute sinusitis often includes empirically administered oral antibiotics with inhibitory activity directed against anaerobic organisms. ${ }^{1,3}$ This study reports on the bacterial organisms isolated from patients with chronic sinusitis and the sensitivity of these organisms to frequently used oral antibiotics. The bacterial pattern identified in this study and the comparison of the inhibitory activity of certain oral antibiotics against these organisms may indicate a need for change in the empiric medical management of chronic and recurrent sinusitis.

\section{Patients and methods}

Between August 10, 1988, and September 21, 1990, a total of 197 patients with chronic sinus disease requiring surgical intervention underwent intranasal sinus surgery at Des Moines General Hospital. Specimens of paranasal sinus mucosa or sinus aspirates were taken from these patients and cultured for aerobic organisms. Anaerobic cultures were also done on the same samples from 143 of the $197 \mathrm{pa}-$ tients. Specimens were collected by removing $\mathrm{mu}-$ cosa that appeared to be diseased from the affected sinus by use of sterile intranasal sinus instruments. In less extensive procedures, the maxillary sinuses were directly aspirated or irrigated with nonbacteriostatic sterile saline solution.

All specimens obtained were submitted by use of a Culturette for aerobic cultures and a BBL PortA-Cul tube-and-swab system (Becton Dickinson Mi-

(continued on page 209) 


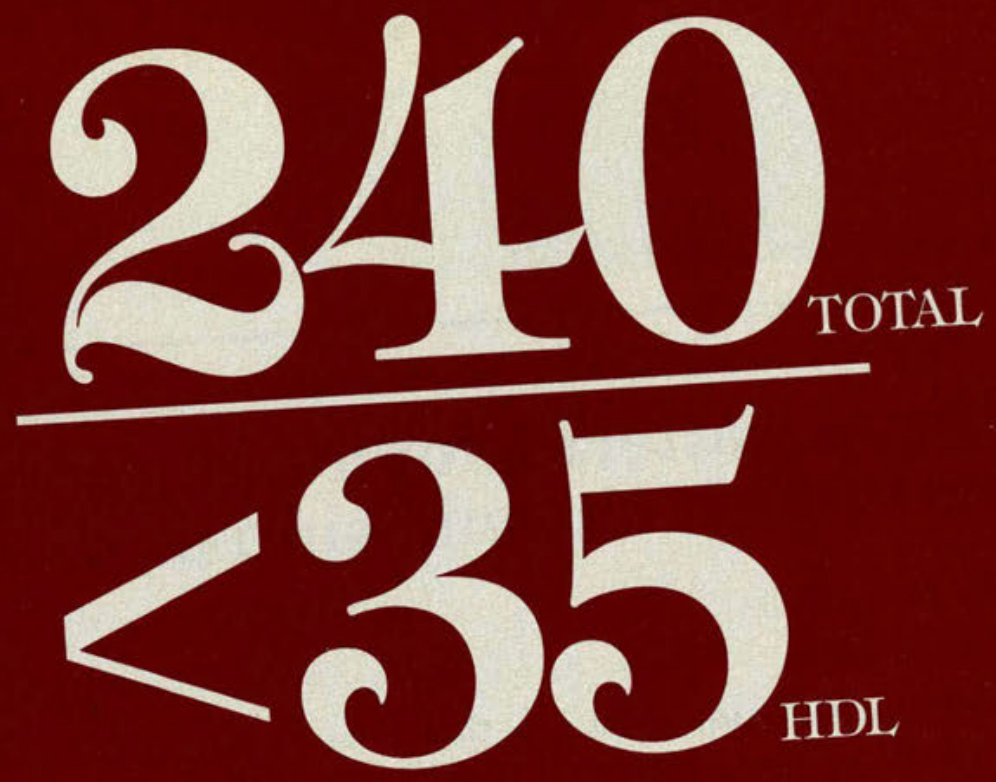

Low HDL with elevated LDL and triglycerides: A common denominator of many heart attack victims

Mixed hyperlipidemias - elevated cholesterol and triglycerides - are common among heart attack victims, and nearly two thirds of people who de baseline myocardial infarction in the PROCAM Trial hail) is not indicated for the treatment level of HDL cholesterol. ${ }^{2}$ LOPID (gemín only lipid abnormality. of patients with low HDL cholesterol as their oniy hipid abnorn

HEART ATTACK PATIENTS

(PROCAM TRIAL) ${ }^{2}$

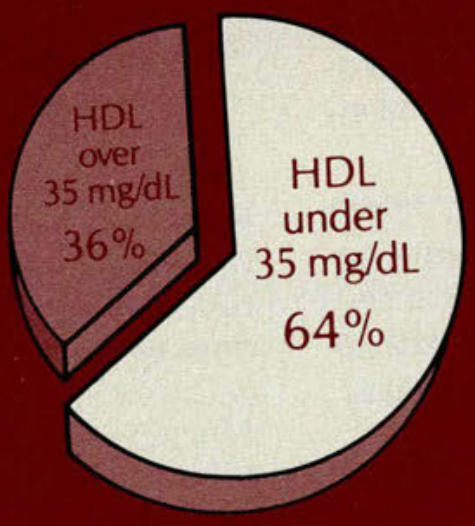




\section{A powerful case for (C) (gemfibrozil) ${ }_{\text {Tablets }}^{600-m}$}

LOPID is indicated for reducing the risk of coronary heart disease in type llb patients with low HDL, in addition to elevated LDL and triglycerides, and who have had an inadequate response to weight loss, diet, exercise, and other pharmacologic agents such as bile acid sequestrants and nicotinic acid.

\section{Raised low HDL 25\%}

-in patients whose baseline HDL was $<35 \mathrm{mg} / \mathrm{dL}$ and median baseline LDL was $186 \mathrm{mg} / \mathrm{dL}$ in the landmark Helsinki Heart Study (HHS). ${ }^{3}$

\section{Reduced heart attack incidence up to $62 \% *$}

-in these HHS patients. ${ }^{3}$ Incidence of serious coronary events was similar for LOPID and placebo subgroups with baseline HDL above the median $(46.4 \mathrm{mg} / \mathrm{dL})^{3}$

\section{RAISES HDL, LOWERS LDL AND TRIGLYCERIDES DRAMATICALLY REDUCES HEART ATTACK}

Contraindicated in patients with hepatic or severe renal dysfunction, including primary biliary cirrhosis, preexisting gallbladder disease, or hypersensitivity to gemfibrozil. LOPID may increase cholesterol secretion into the bile, leading to cholelithiasis. Caution should be exercised when anticoagulants are given in conjunction with LOPID.

-Defined as a combination of definite coronary death and/or definite myocardial infarction. $P=.013 ; 95 \% \mathrm{Cl} 13.3$ to 111.5 .

\footnotetext{
References 1. Goldstein JL, Hazzard WR, Schrott HG, Bierman EL, Motulsky AG. Hyperlipidemia in coronary heart disease. I. Lipid levels in 500 survivors of myocardial infarction. I Clin Invest. 1973;52:1533-1543. 2. Assmann G, Schulte H. PROCAM-Trial: Prospective Cardiovascular Münster Trial. Zürich: Panscientia Verlag: 1986:8-9. 3. Data on file, Medical Affairs Dept, Parke-Davis.
}

Please see last page of this advertisement for warnings, contraindications, and brief summary of prescribing information. 
Lopid ${ }^{`}$ (Gemfibrozil Capsules and Tablets)

Before prescribing, please see full prescribing information. A Brief Summary follows.

CONTRAINDICATIONS.

\section{biliary cirrhosis.}

2. Preexisting gallbladder disease (See WARNINGS)

3. Hypersensitivity to gemfibrozil.

WARNINGS. 1. Because of chemical, pharmacological, and clinical similarities be tween gemfibrozil and clofibrate, the adverse findings with clofibrate in two large clinical studies may also apply to gemfibrozil. In the first of those studies, the Coronary Drug Project, 1000 subjects with previous myocardial infarction were treated for five years with clofibrate. There was no difference in mortality between the clofibrate-treated sub jects and 3000 placebo-treated subjects, but twice as many clofibrate-treated subjects developed cholelithiasis and cholecystitis requiring surgery. In the other study, con ducted by the World Health Organization (WHO), 5000 subjects without known coronary heart disease were treated with clofibrate for five years and followed one year beyond. There was a statistically significant, $29 \%$, higher total mortality in the clofibratetreated than in a comparable placebo-treated control group. The excess mortality was due to a $33 \%$ increase in noncardiovascular causes, including malignancy, post cholecystectomy complications, and pancreatitis. The higher risk of clofibrate-treated subjects for gallbladder disease was confirmed.

During the Helsinki Heart Study and in the $1 \frac{1}{2}$ year follow-up period since the tria was completed, mortality from any cause was $59(2.9 \%)$ in the Lopid group and 55 $(2.7 \%)$ in the placebo group. Mortality from any cause during the double-blind portion of the study was 44 deaths in the Lopid group and 43 in the placebo group. Because of the more limited size of the Helsinki Heart Study, this result is not statisticallysignificantly different from the $29 \%$ excess mortality seen in the clofibrate group in the separate WHO study. Noncoronary heart disease related mortality showed a $58 \%$ greater trend in the Lopid group ( 43 vs 27 patients in the placebo group, $p=0.056$ ) In the Helsinki Heart Study, the incidence of total malignancies discovered during the trial and in the $11 / 2$ years since the trial was completed was 39 in the Lopid group and 29 in the placebo group (difference not statistically significant). This includes 5 basal cell carcinomas in the Lopid group and none in the placebo group $(p=0.06$; historical dat predicted an expected 4.7 cases in the placebo group). GI malignancies and deaths from malignancies were not statistically different between Lopid and placebo sub groups. Follow-up of the Helsinki Heart Study participants will provide further infor. mation on cause-specific mortality and cancer morbidity.

2. A gallstone prevalence substudy of 450 Helsinki Heart Study participants showed a trend toward a greater prevalence of gallstones during the study within the Lopid treatment group $(7.5 \%$ vs $4.9 \%$ for the place bo group, a $55 \%$ excess for the gemfibrozil group). A trend toward a greater incidence of gallbladder surgery was observed for the Lopid group (17 vs 11 subjects, a $54 \%$ ex cess). This result did not differ statistically

from the increased incidence of cholecystectomy observed in the WHO study in the group treated with clofibrate. Both clofibrate and gemfibrozil may increase cholesterol excretion into the bile leading to cholelithiasis. If cholelithiasis is suspected, gallbladde studies are indicated. Lopid therapy should be discontinued if gallstones are found

3 . Since a reduction of mortality from coronary artery disease has not been demonstrated and because liver and interstitial cell testicular tumors were increased in rats, Lopid should be administered only to those patients described in the INDICATIONS AND USAGE section. If a significant serum lipid response is not obtained, Lopid should be discontinued.

4. Concomitant Anticoagulants-Caution should be exercised when anticoagulants are given in conjunction with Lopid. The dosage of the anticoagulant should be reduced to maintain the prothrombin time at the desired level to prevent bleeding complications. Frequent prothrombin determinations are advisable until it has been definitely determined that the prothrombin level has stabilized.

5. Concomitant therapy with Lopid and Mevacor" (lovastatin) has been associated with rhabdomyolysis, markedly elevated creatine kinase (CK) levels and myoglobinuria, leading in a high proportion of cases to acute renal failure. In most subjects who have had an unsatisfactory lipid response to either drug alone, the possible benefit of combined therapy with lovastatin and gemfibrozil does not outweigh the risks of severe myopathy, thabdomyolysis, and acute renal failure (See Drug Interactions). The use of fibrates alone, including Lopid, may occasionally be associated with myositis. Patients receiving Lopid and complaining of muscle pain, tenderness, or weakness should have prompt medical evaluation for myositis, including serum creatine kinase level determination. If myositis is suspected or diagnosed. Lopid therapy should be withdrawn.

6. Cataracts - Subcapsular bilateral cataracts occurred in $10 \%$, and unilateral in $6.3 \%$ of male rats treated with gemfibrozil at 10 times the human dose.

PRECAUTIONS. 1. Initial Therapy - Laboratory studies should be done to ascertain that the lipid levels are consistently abnormal. Before instituting Lopid therapy, every at tempt should be made to control serum lipids with appropriate diet, exercise, weight lo in obese patients, and control of any medical problems such as diabetes mellitus and hypothyroidism that are contributing to the lipid abnormalities.

2. Continued Therapy-Periodic determination of serum lipids should be obtained and the drug withdrawn if lipid response is inadequate after 3 months of therapy.

3. Drug Interactions - (A) Lovastatin: Rhabdomyolysis has occurred with combined gemfibrozil and lovastatin therapy. It may be seen as early as 3 weeks after initiation of combined therapy or after several months. In most subjects who have had an unsatisfac tory lipid response to either drug alone, the possible benefit of combined therapy with lovastatin and gemfibrozil does not outweigh the risks of severe myopathy, rhabdomyolysis, and acute renal failure. There is no assurance that periodic monitoring of creatine kinase will prevent the occurrence of severe myopathy and kidney damage

(B) Anticoagulants: CAUTION SHOULD BE EXERCISED WHEN ANTICOAGUCOAGULANT SHOULD BE REDUCED TO MAINTAIN THE PROTHROMBIN TIME AT THE DESIRED LEVEL TO PREVENT BLEEDING COMPLICATIONS. FREQUENT PROTHROMBIN DETERMINATIONS ARE ADVISABLE UNTIL IT HAS BEEN

DEFINITELY DETERMINED THAT THE PROTHROMBIN LEVEL HAS STABILIZED.

4. Carcinogenesis, Mutagenesis, Impairment of Fertility-Long-term studies have been conducted in rats and mice at one and ten times the human dose. The incidence of benign liver nodules and liver carcinomas was significantly increased in high dose male rats. The incidence of liver carcinomas increased also in low dose males, but this increase was not statistically significant $(p=0.1)$. In high dose female rats, there was a significant increase in the combined incidence of benign, and malignant liver neoplasms. In male and female mice, there were no statistically significant differences

Male rats had a dose-related and statistically significant increase of benign Leydig cell umors at 1 and 10 times the human dose.

Electron microscopy studies have demonstrated a florid hepatic peroxisome prolifera tion following Lopid administration to the male rat. An adequate study to test for peroxsome proliferation has not been done in humans but changes in peroxisome

morphology have been observed. Peroxisome proliferation has been shown to occur in humans with either of two other drugs of the fibrate class when liver biopsies were com pared before and after treatment in the same individual.

Administration of approximately three or ten times the human dose to male rats for 10 weeks resulted in a dose-related decrease of fertility. Subsequent studies demonstrated that this effect was reversed

Pregnancy Category B-Reproduction studies have been performed in the rat at doses 3 and 9 times the human dose, and in the rabbit at 2 and 6.7 times the human dose. These studies have revealed no evidence of impaired fertility in females or harm to the fetus due to Lopid. Minor fetotoxicity was manifested by reduced birth rates observed at the high dose levels. No significant malformations were found among almost 400 offspring from 36 litters of rats and 100 fetuses from 22 litters of rabbits.

There are no studies in pregnant women. In view of the fact that Lopid is tumorigenic in male and female rats, the use of Lopid in pregnancy should be reserved for those patients where the benefit clearly outweighs the possible risk to the patient or fetus.

6. Nursing Mothers - Because of the potential for tumorigenicity shown for gem fibrozil in rats, a decision should be made whether to discontinue nursing or discontinue the drug, taking into account the importance of the drug to the mother

7. Hematologic Changes - Mild hemoglobin, hematocrit and white blood cell decreases have been observed in occasional patients following initiation of Lopid therapy. However, these levels stabilize during long-term administration. Rarely, severe anemia, leukopenia, thrombocytopenia, and bone marrow hypoplasia have been reported. Therefore, periodic blood counts are recommended during the first 12 months id administration.

8. Liver Function -Abnormal liver function tests have been observed occasionally during Lopid administration, including eleva-
tions of AST (SGOT). ALT (SGPT), LDH, bilitions of AST (SGOT), ALT (SGPT), LDH, biliusually reversible when Lopid is discon.

\section{tinued. Therefore periodic liver function studies are recommended and Lopid therapy should be terminated if abnormalities persist. 9. Use in Children - Safety and efficacy in ADVERSE REACTIONS. In the double-blind controlled phase of the Helsinki Heart Study, 2046 patients received Lopid for up to 5 years In that study, the following adverse reactions were statistically more frequent in subjects in the Lopid group (placebo incidence in paren theses): gastrointestinal reactions, $34.2 \%$ \\ BID nal pain, $9.8 \%(5.6 \%)$; acute appendicitis}

600-mg

(histologically confirmed in most cases where data are available), $1.2 \%(0.6 \%)$; atrial (histologically confirmed
fibrillation, $0.7 \%(0.1 \%)$.

Adverse events reported by more than $1 \%$ of subjects, but without a significant differ. ence between groups (placebo incidence in parentheses) were: diarrhea, $7.2 \%(6.5 \%)$ fatigue, $3.8 \%(3.5 \%)$; nausea/vomiting, $2.5 \%(2.1 \%)$; eczema, $1.9 \%(1.2 \%)$; rash, $1.7 \%$ (1.3\%); vertigo, $1.5 \%(1.3 \%)$; constipation, $1.4 \%(1.3 \%)$; headache, $1.2 \%(1.1 \%)$

Gallbladder surgery was performed in $0.9 \%$ of Lopid and $0.5 \%$ of placebo subjects, a $64 \%$ excess, which is not statistically different from the excess of gallbladder surgery observed in the clofibrate compared to the placebo group of the WHO study.

Nervous system and special senses adverse reactions were more common in the Lopid group. These included hypesthesia, paresthesias, and taste perversion. Other adverse reactions that were more common among Lopid treatment group subjects but where a causal relationship was not established include cataracts, peripheral vascular disease, and intracerebral hemorrhage

From other studies it seems probable that Lopid is causally related to the occurrence of musculoskeletal symptoms (See WARNINGS), and to abnormal liver function tests and hematologic changes (See PRECAUTIONS)

Reports of viral and bacterial infections (common cold, cough, urinary tract infections) werc more common in gemfibrozil-treated patients in other controlled clinical trials of 805 patients. Additional adverse reactions that have been reported for gemfibrozil are listed below by system. These are categorized according to whether a causal relationship to treatment with Lopid is probable or not established:

CAUSAL RELATIONSHIP PROBABLE: Gastrointestinal: cholestatic jaundice; Centra/ Nervous System: dizziness, somnolence, paresthesia, peripheral neuritis, decreased libido, depression, headache; Eye: blurred vision; Genitourinary: impotence: Musculoskeletal: myopathy, myasthenia, myalgia, painful extremities, arthralgia, synovitis, rhabdomyolysis (see WARNINGS and Drug Interactions under PRECAU. TIONS); Clinical Laboratory: increased creatine phosphokinase, increased bilirubin, in creased liver transaminases (AST [SGOT], ALT [SGPT]), increased alkaline phosphatase: Hematopoietic: anemia, leukopenia, bone marrow hypoplasia, eosinophilia; Im munologic: angioedema, laryngeal edema, urticaria; Integumentary: exfoliative dermatitis, rash, dermatitis, pruritus.

CAUSAL RELATIONSHIP NOT ESTABLISHED: General: weight loss; Cardiac: extrasys toles; Gastrointestinal: pancreatitis, hepatoma, colitis; Central Nervous System: confusion, convulsions, syncope; Eye: retinal edema; Genitourinary: decreased male fertility: Clinical Laboratory: positive antinuclear antibody; Hematopoietic: thrombocytopenia Immunologic: anaphylaxis, Lupus-like syndrome, vasculitis: Integumentary: alopecia DOSAGE AND ADMINISTRATION. The recommended dose for adults is $1200 \mathrm{mg}$ MANAGEMENT OF OVERDOSE. While there has been no reported case of overdosage symptomatic supportive measures should be taken should it occur References: 1. Frick MH, Elo O, Haapa K, et al: Helsinki Heart Study: Primary preven tion trial with gemfibrozil in middle-aged men with dyslipidemia. N Engl J Med 1987;317:1237-1245. 2. Manninen V. Elo O. Frick MH, et al: Lipid alterations and decline in the incidence of coronary heart disease in the Helsinki Heart Study. JAMA 1988: 260:641-651. 3. Nikkila EA: Familial lipoprotein lipase deficiency and related disorders of chylomicron metabolism. In Stanbury J. B. et al. (eds.): The Metabolic Basis of Inherited Disease, 5th ed., McGraw-Hill, 1983, Chap. 30, pp. $622-642$.
Caution - Federal law prohibits dispensing without prescript

\section{PARKE-DAVIS}

Morris Plains, NJ 07950 USA 


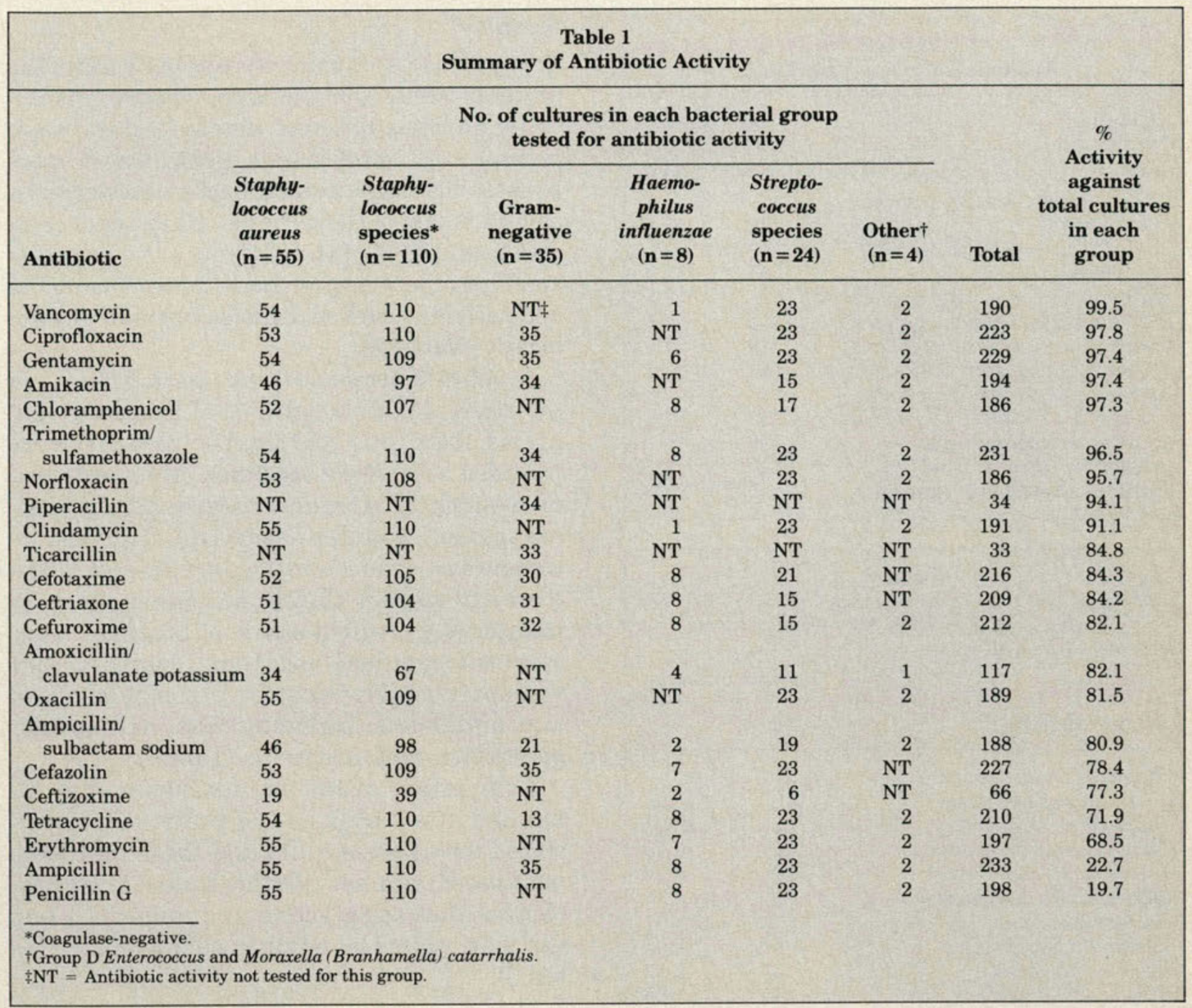

crobiology Systems, Becton Dickinson \& Co, Cockeysville, Md) for anaerobic cultures. The Culturette specimens were plated to $5 \%$ sheep blood, McConkey, and Haemophilus-isolation medium. Specimens were also prepared by Gram's stain and examined. The swabs from the Port-A-Cul system were used to inoculate thioglycollate and trypticase soy broths, reducible blood, and blood agar with neomycin. These plates were incubated at $37^{\circ} \mathrm{C}$. The Haemophilus-isolation medium plates were incubated with $5 \%$ carbon dioxide.

At 24 and 48 hours, the plates and broths were examined for growth. Identification of culture growths and antibiotic sensitivities were reported by use of MicroScan Dried Panels (Baxter Healthcare Cor, Microscan Div, W Sacramento, Ca).

Almost all patients had bilateral sinus disease, and at least one specimen was obtained from the mucosa of each surgical site (the right and left anterior ethmoid sinus cells) or from aspirates of both maxillary sinuses. Therefore, multiple samples for cultures were usually taken from each patient. Among the 174 patients with positive aerobic cultures, $41 \%$ had more than one culture of the same organism with an identical antibiotic sensitivity. In these cases, only one of the identical cultures from each patient was entered into the data to be analyzed.

The activity of 28 antibiotics, included in the panels that are used to test the susceptibility of the different groups of bacteria, was evaluated. These data were then combined to indicate the inhibitory activity of the 28 antibiotics against all the organisms identified. The inhibitory activity of cefazolin was interpreted as indicative of the action of all 
Table 2

Aerobic and Anaerobic Data

\begin{tabular}{|lrr|}
\hline Variable & No. & \multicolumn{1}{c|}{$\%$} \\
\hline Aerobic cultures analyzed & 197 & 100.0 \\
Patients with positive aerobic & & \\
$\quad$ cultures & 174 & 88.3 \\
Patients with multiple aerobic & 55 & 27.9 \\
isolates & 1 & 0.5 \\
Patients with 4 aerobic isolates & 5 & 2.5 \\
Patients with 3 aerobic isolates & 49 & 24.9 \\
Patients with 2 aerobic isolates & 119 & 60.4 \\
Patients with 1 aerobic isolate & & \\
Tested patients with no aerobic & 23 & 11.7 \\
$\quad$ growth & 236 & $\ldots$ \\
Positive aerobic cultures & 143 & $\ldots$ \\
Anaerobic cultures done & 0 & $\ldots$ \\
Positive anaerobic cultures & & \\
\hline
\end{tabular}

Table 3

Yield of 236 Bacterial Isolates From 174 of 197 Patients Tested With Aerobic Cultures

\begin{tabular}{|lrr|}
\hline & \multicolumn{2}{c|}{ Aerobic cultures } \\
\cline { 2 - 3 } Bacterial isolate & No. & $\%$ \\
\hline Staphylococcus species & & \\
(coagulase-negative) & 110 & 46.61 \\
Staphylococcus aureus & 55 & 23.31 \\
Streptococcus pneumoniae & 16 & 6.78 \\
Enterobacter aerogenes & 10 & 4.24 \\
Haemophilus influenzae & 8 & 3.39 \\
Escherichia coli & 7 & 2.97 \\
Klebsiella pneumoniae & 6 & 2.54 \\
Proteus mirabilis & 5 & 2.12 \\
Steptococcus viridans & 4 & 1.69 \\
Serratia species & 2 & 0.85 \\
Streptococcus mitis & 2 & 0.85 \\
Streptococcus salivarius & 2 & 0.85 \\
Morganella morganii & 2 & 0.85 \\
Group D Enterococcus & 2 & 0.85 \\
Moraxella (Branhamella) & & \\
catarrhalis & 2 & 0.85 \\
Citrobacter freundii & 1 & 0.42 \\
Pseudomonas aeruginosa & 1 & 0.42 \\
Acinetobacter lwoffi & 1 & 0.42 \\
Total & $\mathbf{2 3 6}$ & $\mathbf{1 0 0 . 0 0}$ \\
\hline
\end{tabular}

first-generation oral cephalosporins (Table 1). So this information would be useful to the physician treating chronic and recurrent acute bacterial sinusitis with oral antibiotics, parenteral antimicrobials and those antibiotics not tested against all organisms found were excluded from the analysis. The potential empiric usefulness of the remaining antibiotics was compared.

\section{Results}

Bacterial isolates were present in $88.3 \%$ of the patients whose samples were cultured aerobically; multiple different aerobic isolates were present in $27.9 \%$ of these patients. One or more isolates of a single aerobic bacterium were present in $60.4 \%$ of the patients. Cultures of samples from $11.7 \%$ of the patients grew no bacteria. There were no positive cultures among the 143 patients who had samples cultured anaerobically (Table 2 ).

In all, 236 aerobic cultures were included in the study. Multiple cultures of identical organisms from any particular patient were recorded as a single specimen. The most commonly identified organisms were Staphylococcus species (coagulase-negative), Staphylococcus aureus, gram-negative bacilli, and Streptococcus species (Table 3). There were 39 isolates of a virulent strain of Staphylococcus species (coagulase-negative) identified that were particularly resistant to commonly used oral antibiotics, including first- and secondgeneration cephalosporins (Table 4).

Comparison of the six antibiotics that remained after exclusion of the ones administered only parenterally and those that were not tested against all the bacterial groups showed that tetracycline and ampicillin had the least potential empiric effectiveness (Table 5).

\section{Discussion}

Anaerobic bacteria have been implicated as the most likely pathogens in chronic sinusitis, as established in previous studies by Frederick and Braude ${ }^{6}$ and later articles by Brook..$^{5,7}$ Two popular guides ${ }^{2,4}$ and one 1989 article $^{3}$ on the nonsurgical treatment of chronic sinusitis indicate that aerobic bacteria play a secondary role in chronic sinusitis.

It was my clinical observation that aerobic bacteria had a much greater prevalence in chronic sinusitis than previously reported. This observation is supported by Lusk and Muntz ${ }^{9}$ and by Tinkelman and Silk. ${ }^{10}$ An explanation of this variance with previously reported data is not readily apparent, and it was a constant cause for concern during this study. Therefore, both the specimen collection method 


\begin{tabular}{|c|c|c|c|}
\hline \multicolumn{4}{|c|}{$\begin{array}{l}\text { Table } 4 \\
\text { Antibiotic Susceptibility of Staphylococcus Species } \\
\text { (Coagulase-Negative) }\end{array}$} \\
\hline \multirow[b]{2}{*}{ Antibiotic } & \multirow{2}{*}{$\begin{array}{l}\text { Total No. of } \\
\text { cultures } \\
\text { in group }(n=39)\end{array}$} & \multicolumn{2}{|c|}{ Susceptible } \\
\hline & & No. & $\%$ \\
\hline Ciprofloxacin & 39 & 37 & 94.9 \\
\hline Norfloxacin & 37 & 35 & 94.6 \\
\hline Chloramphenicol & 36 & 34 & 94.4 \\
\hline Sulfamethizole & 36 & 33 & 91.7 \\
\hline Trimethoprim/ & & & \\
\hline sulfamethoxazole & 39 & 35 & 89.7 \\
\hline Clindamycin & 39 & 33 & 84.6 \\
\hline Tetracycline & 39 & 20 & 51.3 \\
\hline Erythromycin & 39 & 17 & 43.6 \\
\hline Amoxicillin/clavulanate & & & \\
\hline potassium & 23 & 5 & 21.7 \\
\hline Oxacillin & 38 & 6 & 15.8 \\
\hline Cefazolin (Ancef) & 38 & 6 & 15.8 \\
\hline Cefuroxime (Zinacef, Ceftin) & 33 & 1 & 3.0 \\
\hline Ampicillin & 39 & 1 & 2.6 \\
\hline Penicillin G & 39 & 0 & 0.0 \\
\hline
\end{tabular}

\begin{tabular}{|c|c|c|c|c|c|c|c|c|}
\hline \multirow[b]{3}{*}{ Antibiotic } & \multicolumn{6}{|c|}{$\begin{array}{c}\text { Table } 5 \\
\text { Summary of Antibiotic Activity for Oral Empiric Therapy }\end{array}$} & & \multirow{3}{*}{$\begin{array}{l}\text { \% of } \\
\text { organisms } \\
\text { inhibited } \\
\text { by tested } \\
\text { antibiotic } \\
\text { (all groups } \\
\text { included) }\end{array}$} \\
\hline & \multicolumn{6}{|c|}{$\begin{array}{l}\text { No. of cultures in each bacterial group } \\
\text { tested for antibiotic activity }\end{array}$} & \multirow[b]{2}{*}{ Total } & \\
\hline & $\begin{array}{c}\text { Staphy- } \\
\text { lococcus } \\
\text { aureus } \\
(\mathbf{n}=55)\end{array}$ & $\begin{array}{l}\text { Staphy- } \\
\text { lococcus } \\
\text { species* } \\
(\mathrm{n}=110)\end{array}$ & $\begin{array}{c}\text { Gram- } \\
\text { negative } \\
(\mathbf{n}=35)\end{array}$ & $\begin{array}{c}\text { Haemo- } \\
\text { philus } \\
\text { influenzae } \\
(\mathrm{n}=8)\end{array}$ & $\begin{array}{l}\text { Strepto- } \\
\text { coccus } \\
\text { species } \\
(\mathbf{n}=24)\end{array}$ & $\begin{array}{l}\text { Other }{ }_{(\mathbf{n}=4)}\end{array}$ & & \\
\hline Ciprofloxacin & 53 & 110 & 35 & NT $\neq$ & 23 & 2 & 223 & 97.8 \\
\hline $\begin{array}{l}\text { Trimethoprim/ } \\
\text { sulfamethoxazole }\end{array}$ & 54 & 110 & 34 & 8 & 23 & 2 & 231 & 96.5 \\
\hline Cefuroxime & 51 & 104 & 32 & 8 & 15 & 2 & 212 & 82.1 \\
\hline Cefazolin & 53 & 109 & 35 & 7 & 23 & NT & 227 & 78.4 \\
\hline Tetracycline & 54 & 110 & 13 & 8 & 23 & 2 & 210 & 71.9 \\
\hline Ampicillin & 55 & 110 & 35 & 8 & 23 & 2 & 233 & 22.7 \\
\hline $\begin{array}{l}\text { *Coagulase-negative. } \\
\text { +Group D Enterococcl } \\
\text { † NT = Antibiotic ac }\end{array}$ & ot teste & $\begin{array}{l}\text { ihamello } \\
\text { s group. }\end{array}$ & halis. & & & & & \\
\hline
\end{tabular}

and laboratory technique were scrutinized.

Variations between the different studies in the technique of collecting specimens (intranasal vs extranasal), the age of the patient population (Lusk and Muntz ${ }^{9}$ and Tinkelman and Silk $^{10}$ both reported only on a pediatric population), and the use of antibiotics preoperatively (at least one study ${ }^{7}$ excluded patients who had received antibiotics preoperatively) could certainly have a bearing on the culture results. Additional studies, such as one analyzing the preoperative administration of antibiotics, will be required to determine the significance of these differences.

In their investigation, Lusk and Muntz ${ }^{9}$ indicated that Staphylococcus species (coagulasenegative) is considered a contaminant. It is my opinion that Staphylococcus species (coagulasenegative) represents a true chronic sinusitis pathogen. This opinion is based partly on the 
presence of 39 Staphylococcus species (coagulase-negative) isolates ( $35 \%$ of the staphylococcal and $16 \%$ of the total number of bacterial isolates) that were particularly resistant to commonly used oral antibiotics.

\section{Summary}

Bacterial isolates obtained from surgical patients with chronic sinusitis in whom conservative medical therapy failed demonstrated strong evidence that aerobic bacteria, rather than anaerobic organisms, are the more common pathogens in chronic and recurrent bouts of bacterial sinusitis. The bacteria isolated from specimens obtained during surgery for chronic sinusitis were more resistant to penicillin, erythromycin, tetracycline, ampicillin, and first-generation oral cephalosporins than to ciprofloxin, trimethoprim/sulfamethoxazole, and cefuroxime axetil.

\section{Acknowledgment}

The author wishes to thank Terrance O. Kurtz, DO; Gary Hoff, DO; Francis P. Smyth, and Anita G.
Hoyt for their assistance in the preparation of this article.

\section{References}

1. Hoyt WH III: Current concepts in management of sinus disease. JAOA 1990;90:913-919.

2. Fairbanks DNF: Pocket Guide to Antimicrobial Therapy in Otolaryngology - Head and Neck Surgery, ed 5. Washington, DC, American Academy of Otolaryngology-Head and Neck Surgery Foundation, Inc, 1989.

3. Malow JB, Creticos CM: Nonsurgical treatment of sinusitis. Otolaryngol Clin North Am 1989;22:809-818.

4. Sanford JP: Guide to Antimicrobial Therapy 1990. West Bethesda, Md, Antimicrobial Therapy, Inc, 1990, pp 26-27.

5. Brook I: Aerobic and anaerobic bacterial flora of normal maxillary sinuses. Laryngoscope 1981;91:372-376.

6. Frederick J, Braude AL: Anaerobic infection of the paranasal sinuses. N Engl J Med 1974;290:135-137.

7. Brook I: Bacteriology of chronic maxillary sinusitis in adults. Ann Otol Rhinol Laryngol 1989;98:426-428.

8. Hoyt WH III: Aerobic bacterial patterns in chronic sinusitis: A study of patients from central Iowa. Hawkeye Osteopathic Journal, Jan-Feb 1990, pp 10-11.

9. Muntz HR, Lusk RP: The bacteriology of the ethmoid bullae in children with chronic sinusitis. Arch Otolaryngol Head Neck Surg 1991;117:179-181.

10. Tinkelman DG, Silk HJ: Clinical and bacteriologic features of chronic sinusitis in children. Am J Dis Child 1989;143:938941. 